\title{
Asymptomatic Carotid Artery Stenosis among Patients with Type II Diabetes Mellitus
}

Sadia Shahid, Abdul Latif Khattak, Karamat Hussain Shah Bukhari, Raffi Uddin, Raees Iqbal Khan, Mohammad Shahbaz Amin

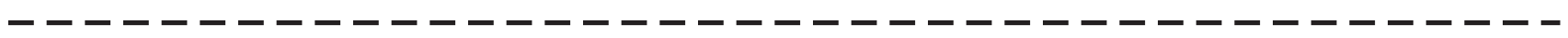
ABSTRACT

Objectives: To assess Carotid artery intima-media thickness in patients with type II diabetes mellitus.

Study design and setting: This descriptive cross-sectional study was conducted at Department of Medicine, CMH Quetta from June 2018 to May 2019.

Methodology: Total 176 known type II diabetes mellitus (DM) patients were included in study. Age ranged from 30-70 years. Patients using statin drugs, chronic kidney disease and decompensated liver cirrhosis were excluded. Carotid artery ultrasonography was carried out by radiologist. Carotid artery intima-media thickness (CIMT) was achieved with a 7 MHz B-mode ultrasound system. The intima-media thickness (IMT) was demarcated as the distance between the leading edge of the luminal echo to the leading edge of the adventitia of the media. This distance was measured during the diastolic phase. This was measured $3 \mathrm{~cm}$ before the carotid bifurcation. Also, carotid bifurcation and internal carotid artery $2 \mathrm{~cm}$ distally from the carotid bifurcation was scanned.

Results: Mean age was $47.86 \pm 6.46$ years. Most of the patients $125(71.02 \%)$ were consisted of 30 to 50 years of age. Among them the 176 patients, $92(52.27 \%)$ were male and $84(47.73 \%)$ were females. Male to female ratio comprised of 1.1:1. Results further revealed that $43(24.43 \%)$ patients showed asymptomatic Carotid artery intima-media thickness. Rest there was no asymptomatic Carotid artery intima-media thickness in $133(75.57 \%)$ patients.

Conclusion: This study determined that the frequency of asymptomatic Carotid artery intima-media thickness in patients with type II diabetes mellitus is quite high.

Keywords: Asymptomatic, Carotid artery intima-media thickness, Type 2 diabetes.

How to cite this Article:

Shahid S, Khattak AL, Bukhai KHS, Uddin R, Khan RI, Amin MS. Asymptomatic Carotid Artery Stenosis among Patients with Type II Diabetes Mellitus. J Bahria Uni Med Dental Coll. 2021; 11(1):27-30 DOI: https://doi.org/10.51985/AITH5490

This is an Open Access article distributed under the terms of the Creative Commons Attriution Non Commercial Liciense (http:// creativecommons/org/licences/by-nc/4.0) which permits unrestricted non commercial use, distribution and reproduction in any medium, provided the original work is properly cited.

- - - - - - - - - - - - - - - - - - - - - - - - - - -

\section{INTRODUCTION:}

Main types of diabetes mellitus (DM) includes: type I or

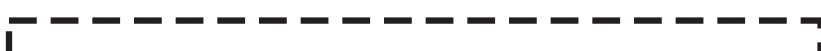

Sadia Shahid

Senior Registrar, Department of Medicine

I Combined Military Hospital, Quetta

I Abdul Latif Khattak

I Associate Professor, Department of Medicine

Combined Military Hospital, Quetta

I Karamat Hussain Shah Bukhari

Assistant Professor, Department of Medicine

Combined Military Hospital, Lahore

I

Raffi Uddin

Assistant Professor, Department of Medicine

I Combined Military Hospital, Lahore

I Raees Iqbal Khan

I Senior Registrar, Department of Medicine

Combined Military Hospital, Quetta

Email: iqbalraees@yahoo.com

Mohammad Shahbaz Amin

I Associate Professor, Department of Pathology

I Lahore Medical and Dental College, Lahore

Received: 28-Apr-2020

I Accepted: 05-Nov-2020

I

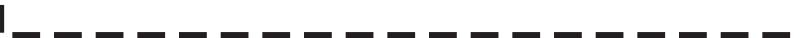

insulin dependent DM or juvenile diabetes, type II or noninsulin dependent DM or adult-onset diabetes and gestational diabetes. ${ }^{1,2}$ Occurrence of diabetes mellitus is $10-14 \%$ throughout world. ${ }^{2}$ Diabetes mellitus type 2 (formerly noninsulin-dependent diabetes mellitus (NIDDM) or adultonset diabetes refers to a metabolic disorder. It is considered as high blood glucose levels in the presence of comparative insulin resistance and deficiency and in Type I disoder due to ablolute insulin deficiency ${ }^{3}$. This critical insulin deficiency is due to destruction of islet cells in pancreas. ${ }^{4}$

Destructive effects of hyperglycemia can be categorized as macro-vascular complications. Macrovascular complications include coronary artery disease, peripheral arterial disease, and stroke. While micro vascular complications are diabetic nephropathy, neuropathy and retinopathy. ${ }^{5}$ Altered platelet morphology and functions have been found in diabetic patients. This pathology is related to the pathological processes. This pathological process poses high risk of vascular disease. ${ }^{6}$ Diabetes Mellitus (DM) has emerged as most prevalent non-communicable diseases worldwide. ${ }^{7}$ It has become the fourth or fifth important cause of mortality among high-income countries. ${ }^{7}$ From 2009 till 2034, count 
of people with diagnosed and undiagnosed diabetes would go on rise from 23.7 million to 44.1 million in United States. ${ }^{8}$ It is anticipated that by 2025 about 380 million people would suffer from type 2 diabetes. Population having impaired glucose tolerance in the world would count about 418 million. ${ }^{9}$ Major risk factor for cerebrovascular events is stenosis of the internal carotid artery. Those individuals with signs and symptoms of ischemic stroke plus a carotid stenosis showed $50 \%$ high risks of a recurrent event. These patients have a risk of stroke equal to $21 \%$ at 2 weeks after the first transient Ischaemic stroke or stroke. Also, risk is $32 \%$ at 12 weeks. ${ }^{10}$ Asymptomatic Carotid artery intima-media thickness is directly proportional to a higher risk of stroke. Recent research revealed stroke risks of about $0.5 \%$ per year for $70 \%$ to $99 \%$ ACAS transient ischemic stroke patients. ${ }^{11}$ Therefore; the rationale of the study is to estimate the Carotid artery intima-media thickness in our local diabetic patients. The outcome of this study will be a parameter for developing forthcoming research approaches. This will also guide us for developing mechanisms of avoiding future cerebrovascular events in type 2 Diabetes Mellitus patients.

\section{METHODOLOGY:}

This descriptive, cross-sectional study was performed in outpatient and indoor patients in Department of Medicine, CMH Quetta cantonment from June 2018 to May2019 for one year. Approval of Combined Military Hospital, Quetta ethical committee has been obtained numbered IRB/019. Sample Size was calculated by keeping $20.8 \%$ proportion of carotid artery intima-media thickness in patients with $\mathrm{DM}^{12}$ with $95 \%$ confidence interval and $6 \%$ margin of error using World Health Organization (WHO) sample size calculator. Hence 176 was the calculated sample size. Nonprobability, consecutive sampling technique was carried out in both outpatient and indoor admitted patients. Informed and written consent was taken from all patients included in the study. Patients fulfilled inclusion criteria by history and examination. Patients with type-II DM for two years duration, without signs or symptoms of focal or global neurological deficit, male and female with age range between 30 to 70 years, patients without target organ damage like retinopathy, left ventricular hypertrophy and nephropathy were included in study. Patients having history of using statins, fibrate drugs, and multivitamins especially thiamine supplements, diagnosed history of renal failure, diagnosis of decompensated liver failure on medical records and laboratory investigations were excluded from the study. Carotid artery ultrasonography was done by an experienced specialist radiologist for the vascular ultrasonography performed by Doppler. Carotid artery intima-media thickness was assessed with a $7 \mathrm{MHz}$ B-mode ultrasound system. The IMT stands for the distance between the foremost edges of the luminal echo to the inner edge of the adventitia of the media. This distance were measured during the diastolic phase. The B-mode scanning procedure comprised the scanning of the right and left common carotid arteries ( $3 \mathrm{~cm}$ before the carotid bifurcation). It also includes the internal carotid artery $2 \mathrm{~cm}$ distally from the carotid bifurcation. It was measured in $\mathrm{mm}$ and a value exceeding $7 \mathrm{~mm}$ was considered as carotid artery stenosis. All data was endorsed on the Performa. Data entered and analyzed in SPSS version 22. Mean + SD were calculated for quantitative variables like age and extent of DM. Frequencies and percentages were obtained for categorical variables like gender and Carotid artery intima-media thickness. Carotid artery intima-media thickness was stratified among age, gender and duration of diabetes. It was performed to calculate effect modifications by chi square test. The $\mathrm{p}$ value of $<0.05$ was considered as statistically significant.

\section{RESULTS:}

Age range was between 30 to 70 years with mean age of $47.86 \pm 6.46$ years. Main stream of the patients $125(71.02 \%)$ were among age 30 to 50 years as revealed in Table I. Total patients were 176 patients out of which $92(52.27 \%)$ were male and $84(47.73 \%)$ were females. Male to female ratio is 1.1:1. Mean period of disease was $7.11 \pm 3.89$ years. Asymptomatic Carotid artery intima-media thickness was observed in 43 (24.43\%) patients, whereas no evidence of asymptomatic carotid artery intima-media thickness in 133 (75.57\%) patient (Table II). Also, presence of asymptomatic carotid artery intima-media thickness was calculated on age groups. It was observed that there was no significant difference between different age groups. Stratification of asymptomatic carotid intima-media thickness with respect to age, gender and duration of diabetes mellitus type II is shown in Table II. This study also showed no significant

Table-I: Age distribution of patients $(\mathrm{n}=176)$.

\begin{tabular}{|c|c|}
\hline Age (in years) & $\mathrm{N}(\%)$ \\
\hline $\mathbf{3 0 - 5 0}$ & $125(71.02)$ \\
\hline $\mathbf{5 1 - 7 0}$ & $51(28.98)$ \\
\hline Total & $176(100)$ \\
\hline
\end{tabular}

Table II: Stratification of asymptomatic carotid artery intima-media thickness with age, gender and duration of diabetes mellitus

\begin{tabular}{|c|c|c|c|}
\hline \multirow{2}{*}{ Age (years) } & \multicolumn{2}{|c|}{$\begin{array}{c}\text { Asymptomatic carotid } \\
\text { artery stenosis }\end{array}$} & \multirow{2}{*}{ P-value } \\
\cline { 2 - 3 } & Yes & No & \\
\hline $30-50$ & 32 & 93 & \multirow{2}{*}{0.572} \\
\hline $51-70$ & 11 & 40 & \\
\hline Gender & Yes & No & \multirow{2}{*}{0.604} \\
\hline Male & 21 & 71 & \\
\hline Female & 22 & 62 & \multirow{2}{*}{0.805} \\
\hline Duration (years) & Yes & No & \\
\hline$<5$ & 23 & 74 & \\
\hline$>5$ & 20 & 59 & \\
\hline
\end{tabular}


Table-III: Distribution of patients according to duration of DM $(n=176)$

\begin{tabular}{|c|c|}
\hline Duration (in years) & No. of Patients(\%) \\
\hline$<\mathbf{5}$ & $97(55.11)$ \\
\hline$>\mathbf{5}$ & $79(44.89)$ \\
\hline
\end{tabular}

Mean $\pm \mathrm{SD}=\mathbf{7 . 1 1} \pm \mathbf{3 . 8 9}$ years

difference between male and female. Table III has shown the distribution of asymptomatic carotid intima-media thickness with reference to span of disease.

\section{DISCUSSION:}

Diabetes has been demarcated as an independent risk factor for the occurrence of high-grade carotid artery intima-media thickness in the general population. ${ }^{13}$ Type-II Diabetes (T2D) carries a considerable risk factor for the advancement of atherosclerosis. It is measured by increase in carotid intimamedia thickness (CIMT). It is expressed in length unit per patient in 1 year. It is associated with the incidence of plaques on the internal carotid artery in 1-2 years. ${ }^{14,15}$ We have performed this study to estimate and determine the frequency of asymptomatic carotid artery intima-media thickness in patients with type II diabetes mellitus.

Age in this study ranged between 30 to 70 years. Mean age calculated as $47.86 \pm 6.46$ years. Most of the patients 125 $(71.02 \%)$ were in range of 30 to 50 years of age. Among 176 patients, $92(52.27 \%)$ were male and 84 (47.73\%) were females. Male to female ratio remained 1.1:1. Asymptomatic carotid artery intima-media thickness was observed in 43 $(24.43 \%)$ patients. However, there was no evidence of asymptomatic carotid artery intima-media thickness in 133 (75.57\%) patients. In one study, $19.2 \%$ of diabetic patients had significant carotid artery intima-media thickness compared to $9 \%$ in non-diabetic patients. ${ }^{16}$ In another study, $20.8 \%$ of patients with Diabetes mellitus were reported to have carotid artery intima-media thickness. ${ }^{12}$ Asymptomatic significant stenosis was lesser in few areas of the world such as $1.2 \%$ from Austria, ${ }^{17} 1.3 \%$ in Australia., ${ }^{18} 1.4 \%$ in Netherlands, ${ }^{19} 1.5 \%$ from Taiwan, ${ }^{20}$ and $2.1 \%$ from France. ${ }^{21}$ The incidence of asymptomatic significant carotid artery intima-media thickness was found as being 5.4\% in the Dutch population, ${ }^{22} 3.9 \%$ in Italians, ${ }^{23} 4.6 \%$ from USA, ${ }^{24}$ and $4.2 \%$ from Russia. ${ }^{25}$ Ethnicity and basic genetic makeup with alteration from external factors such as diet, lifestyle, and stress may contribute to this pathological process. This study displayed an obvious increment in the risk (6.2 times) of developing ICA stenosis with diabetes of more than 15year duration $(\mathrm{OR}=6.2 ; 95 \% \mathrm{CI}$ : 3.41-11.3).

In diabetic individuals, carotid artery disease is often noticed at more advanced stages of the disease as compared with the overall population. It is observed that in diabetic subjects, the arteriosclerotic process grows at faster rate and much earlier as compared to non-diabetic patients. Diabetic patients

remain asymptomatic for carotid artery disease for longer periods. Diabetic patients have large volume atherosclerotic plaques and are usually characterized by their large lipid cores. This pathologic process leads to large remodeling rates in the involved vascular segment. These segments have thin fibrous caps with strong inflammatory process which make them more susceptible to rupture. This process becomes basis for an acute coronary event. Diabetic patients also have additional extensive, diffuse and severe coronary artery involvement. All above mentioned are features are associated with a bad prognosis. Multivariate analysis showed that non-obstructive and even obstructive CAD analyzed by coronary CTA points towards prognostic indicators for asymptomatic T2DM patients ${ }^{26}$. Prospective, long duration clinical studies ${ }^{27}$, revealed that acceptable glycemic control related with early management of other cardiovascular risk factors. These cardiovascular risk factors include such as obesity, hypertension and dyslipidemia. Their early management is linked with lower morbidity and mortality in diabetic patients. Precise screening methods are essential for evaluating diabetic patients who are vulnerable for Stroke development. It will lead to reduction of the cost and morbidity related with conventional carotid angiogram. Duplex Doppler ultra-sonography has been turned out asbroadly recognized noninvasive screening method. ${ }^{28}$ In routine patient follow up only symptomatic patients are evaluated for carotid duplex examination. But fresh data displays that those patients with asymptomatic carotid artery stenosis of $60 \%$ or more have a reduced 5 years risk of ipsilateral stroke on elective carotid endarterctomy. ${ }^{29}$ In the context of these results, it has turned out to be an essential to assess carotid artery disease in all Type 2 Diabetics. It should be done in all diabetic patients whether they are symptomatic or asymptomatic to evaluate cerebrovascular disease. This will aid in risk stratification and developing sophisticated management plan.

\section{CONCLUSION:}

This study concluded that the frequency of asymptomatic carotid artery intima-media thickness in patients with type II diabetes mellitus is fairly high. It is recommended that proper screening should be carried out to estimate frequency of asymptomatic carotid artery intima-media thickness incidence in patients with type II diabetes mellitus. This will help in reduction of their morbidity and will have significant impact on mortality.

Authors Contribution:
Sadia Shahid: Idea, design, data collection
Abdul Latif Khattak: Data collection, data analysis
Karamat Hussain Shah Bukhari: Introduction, manuscript I
writing
Raffi Uddin: Data interpretation, abstract writing
Raees Iqbal Khan: Data interpretation, discussion
Mohammad Shahbaz Amin: Data analysis and interpretation I




\section{REFERENCES:}

1. Shoback, Gardner DG, Dolores. Greenspan's basic \& clinical endocrinology. 9th ed. New York: McGraw-Hill Medical. 2011; Chap 17.

2. Khanzada MA, Siyal NA, Mirza SA, Memon A, El-Muttaqi A, Mirza AA. Frequency and types of diabetic maculopathy in type II diabetes. Pak J Surg. 2013;29(2):139-42.

3. Vijan S. Type 2 diabetes. Ann Intl Med. 2010;152(5):31-15.

4. Ludwig J, Sanbonmatsu L, Gennetian L, Adam E, Duncan GJ, Katz LF, et al. Neighborhoods, obesity, and diabetes--a randomized social experiment. $\mathrm{N}$ Engl J Med. 2011;365(16):1509-19.

5. Inzucchi SE, Bergenstal RM, Buse JB, Diamant M, Ferrannini E, Nauck M, et al. Management of hyperglycaemia in type 2 diabetes: a patient-centered approach. Position statement of the American Diabetes Association (ADA) and the European Association for the Study of Diabetes (EASD). Diabetologia. 2012;55(6):1577-96.

6. Park BJ, Shim JY, Lee HR, Jung DH, Lee JH, Lee YJ. The relationship of platelet count, mean platelet volume with metabolic syndrome according to the criteria of the American Association of Clinical Endocrinologists: a focus on gender differences. Platelets. 2012;23(1):45-50.

7. DW, PZ, TA, MP, AJ, RA. The Rising Prevalence of Diabetes and Impaired Glucose Tolerance. Diabetes Care 2012;25(5):829-834.

8. Leong A, Porneala B, Dupuis J, Florez JC, Meigs JB. Type 2 diabetes genetic predisposition, obesity, and all-cause mortality risk in the US: a multiethnic analysis. Diabetes care. 2016;39(4):539-46.

9. Zimmet PZ, Alberti KG. Epidemiology of diabetes — status of a pandemic and issues around metabolic surgery. Diabetes care. 2016;39(6):878-83.

10. Kakisis JD, Avgerinos ED, Antonopoulos CN, Giannakopoulos TG, Moulakakis K, Liapis CD. The European Society for Vascular Surgery guidelines for carotid intervention: an updated independent assessment and literature review. Eur J VascEndovasc Surg. 2012;44:238-243.

11. den Hartog AG, Achterberg S, Moll FL, Kappelle LJ, Visseren FL, van der Graaf Y, et al. Asymptomatic carotid artery stenosis and the risk of ischemic stroke according to subtype in patients with clinical manifest arterial disease. Stroke 2013;44(4):1002-7.

12. J, K, S, KM. Measurement of intima media thickness of carotid artery by B-mode ultrasound in healthy people of India and Bangladesh, and relation of age and sex with carotid artery intima media thickness: An observational study. J Cardiovasc Dis Res. 2012;3(2):128-131.

13. Taneja S, Chauhan S, Kapoor PM, Jagia P, Bisoi AK. Prevalence of carotid artery stenosis in neurologically asymptomatic patients undergoing coronary artery bypass grafting for coronary artery disease: Role of anesthesiologist in preoperative assessment and intraoperative management. Annals of cardiac anaesthesia. 2016; 19(1):76.

14. Cardoso CR, Salles GC, Leite NC, Salles GF. Prognostic impact of carotid intima-media thickness and carotid plaques on the development of micro-and macrovascular complications in individuals with type 2 diabetes: the Rio de Janeiro type 2 diabetes cohort study. Cardiovascular Diabetology. 2019;18(1):2.
15. Zhang M, Wen X, Zhou C, Huang J, He Y. Carotid intimamedia thickness and plaques in internal carotid artery as surrogate markers of lower limb arterial lesions in Chinese patients with diabetic foot. Brazilian Journal of Medical and Biological Research. 2019;52(7).

16. Matthias W. Lorenz, Jackie F. Price, Christine Robertson, Michiel L. Bots, Joseph F. Polak, Holger Poppert et.alCarotid Intima-Media Thickness Progression and Risk of Vascular Events in People with Diabetes: Results From the PROGIMT Collaboration.. 2015; 38: 1921-1929.

17. Yang B, Li TD, Wang JS, Zhi G, Jin WS, Xu Y. Insulin resistance and carotid atherosclerosis in 221 patients with potential hyperglycemia. Chin Med Sci J. 2005;20(2):108-111.

18. Horner S, Augustin M, Schmidt R, Fazekas F, Ott E, Niederkorn K. Long-term transcranial Doppler sonography and magnetic resonance imaging for evaluation of silent cerebral embolism in cerebrovascular asymptomatic probands. Turk SerebrovaskulerHastaliklarDergisi2005;11:9-12.

19. Langsfeld M, Lusby RJ. The spectrum of carotid artery disease in asymptomatic patients. J Cardiovasc Surg 1988;29:68791.

20. Mineva PP, Manchev IC, Hadjiev DI. Prevalence and outcome of asymptomatic carotid stenosis: A population-based ultrasonographic study. Eur J Neurol 2002;9:383-8.

21. Su TC, Jeng JS, Chien KL, Sung FC, Hsu HC, Lee YT. Hypertension status is the major determinant of carotid atherosclerosis: A community-based study in Taiwan. Stroke 2001;32:2265-71.

22. Josse MO, Touboul PJ, Mas JL, Laplane D, Bousser MG. Prevalence of asymptomatic internal carotid artery stenosis. Neuroepidemiology 1987;6:150-2.

23. van Merode T, Hick P, Hoeks PG, Reneman RS. Serum $\mathrm{HDL} /$ total cholesterol ratio and blood pressure in asymptomatic atherosclerotic lesions of the cervical carotid arteries in men. Stroke 1985;16:34-8.

24. Willeit J, Kiechl S. Prevalence and risk factors of asymptomatic extracranial carotid artery atherosclerosis. A population-based study. ArteriosclerThromb1993; 13:661-8.

25. Pujia A, Rubba P, Spencer MP. Prevalence of extracranial carotid artery disease detectable by echo-Doppler in an elderly population. Stroke 1992; 23:818-22.

26. Peigang Tian, Xiangyang Zheng, Mingzhi Li, Weiwei Li, QingliangNiu. Long-term prognostic value of coronary computed tomography angiography for asymptomatic patients with CAD in type 2 diabetes mellitus. . 2019; 18: 747-754.

27. 10. Gaede P, Vedel P, Parving H, Pedersen O. Intensified multifactorial intervention in patients with type 2 diabetes mellitus and microalbuminuria: The STENO type 2 randomised study. Lancet. 1999; 353:617-22.

28. Johannes Rübenthaler, Maximilian Reiser, Dirk-André Clevert.Diagnostic vascular ultrasonography with the help of color Doppler and contrast-enhanced ultrasonography.. 2016; 35: 289-301.

29. Yang Li, Jing-Jing Yang, Su-Hui Zhu, Biao Xu, Lian Wang. Long-term efficacy and safety of carotid artery stenting versus endarterectomy: A meta-analysis of randomized controlled trials.. 2017; 12(7).

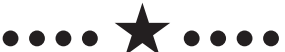

